\title{
Electronic Markets on big data services
}

\author{
Rainer Alt ${ }^{1} \cdot$ Hans-Dieter Zimmermann ${ }^{2}$
}

(C) Institute of Applied Informatics at University of Leipzig 2017

Dear readers,

In the last editorial, the scenario was similar: two special issues were combined in one final issue and the editorial piece provided an opportunity to reflect about the relationship between these two special themes. Issue 27/2 included the special issues on supply chain management and on the academic publishing market and the flow perspective from supply chain management was found valuable for identifying and eliminating shortcomings in current publishing processes (Alt 2017). The present issue now comprises one special issue on "Service oriented e-business development" and another on "Big Data Analytics in Electronic Markets". Obviously, both topics - service-orientation as well as big data - are more than multifaceted in nature and have a significant legacy. The following aims to provide some additional structure to the special issue topics and to explore relationships that partially are also addressed in the contributions of the special issues.

\section{Data in electronic markets}

Although the term big data has only received broad attention in the last five to ten years, the underlying growth of data has been a topic of concern since the mid-twentieth century. The

Rainer Alt

rainer.alt@uni-leipzig.de

Hans-Dieter Zimmermann

hansdieter.zimmermann@fhsg.ch

1 Information Systems Institute, Leipzig University, Grimmaische Str. 12, 04109 Leipzig, Germany

2 FHS St. Gallen, University of Applied Sciences, Rosenbergstrasse 59, 9000 St. Gallen, Switzerland projections on the growing number of scientific papers and journals as well as the overall inventories in libraries led to the notion of "information explosion" and in 1975 it was found "that information supply is increasing much faster than information consumption". Information technology (IT) was successively recognized important in efficiently handling, storing and retrieving this amount of data (Press 2013). In this vein, Bryson et al. (1999) discuss data storage and compression techniques under the title "big data for scientific visualization", which they see as a prerequisite for obtaining scientific insights. Today, the world of big data still distinguishes between the characteristics of the data (e.g. the well-known three V's for volume, variety, and velocity), the technological infrastructure (e.g. the database technologies, such as Hadoop, Hana or System G) and the analytical techniques for analyzing and processing the data (e.g. statistical analytics, ontology engineering or text recognition).

Besides the technological disciplines, such as computer and data science, the opportunities and risks of big data have engaged a variety of disciplines from management, marketing, information systems, to law and social sciences. In the field of electronic commerce several researchers have recently outlined the directions for further research (e.g. (Agarwal and Dhar 2014), (Loebbecke and Picot 2015), (Akter and Wamba 2016). For electronic markets, the three basic characteristics typically appear as well. Especially on multisided market platforms, data is created in large quantities (volume) from various sources along the transaction process in the steps information, contracting, settlement and community. The format of these data is heterogeneous in nature (variety) and the availability is often in real time (velocity) as far as the platform operates on real-time technological infrastructures. Harvesting data on these platforms was already present in early electronic markets. For example, the computer reservation systems (CRS) in the airline industry, which originated in the 1970s (Copeland and 
McKenney 1988), stored passenger data in so-called passenger name records (PNR). These PNRs allowed the airlines to establish passenger profiles and to derive valuable information on customer demand. Since CRS evolved to multisided marketplaces, airlines that operated these systems were also in a position to obtain insight into the transaction data of competitors and could complete passenger profiles even if customers were traveling with competing airlines. Obviously, this source on market intelligence represented a competitive advantage that spurred ideas to establish a data-driven business model:

"In July 1998, top officers of the Sabre Group, operator of the Sabre reservation system, gave an interview to PC Week in which they spoke about a planned project intended to provide the airline and other industries with a treasure trove of passenger information - "a potential gold mine." By knowing who is flying where, when and for how much money, they explained, Sabre could gather valuable data to sell to airlines and other businesses, such as travel agencies, hotels and real estate firms. Sabre could find, for example, who is flying to a specific city in the next three weeks." (Swift 2001, 227).

\section{Centralized and decentralized markets}

This statement points at the first application of big data in electronic markets and underlines the privilege of the providers of centralized platforms to "listen" to interactions conducted via his system. Obviously, these providers have an interest in applying big data technologies to derive information and knowledge from the interactions occurring on their platform. Amazon has become widely known to master this game and to provide customers with tailored postings and offerings on this basis. In the digital world, all user interactions and machine operations create event logs that allow the construction of user behavior patterns and rich contextual models. Figure 1 illustrates some exemplary data that emerges during transactions on electronic markets. It ranges from structured (mainly transaction data) to unstructured (mainly textual data expressed in opinions, complaints or experience reports) and the analytical functionalities of big data technologies are important to establish individual as well as aggregated profiles. A second application case may be found in many of the recent (big) data-driven business models, where electronic platforms (e.g. Airbnb, Uber) enable the collection and analysis of usage-/location-based data.

As mentioned above, providers of centralized platforms are also in a position to develop the collection and analysis of data on their platform into a business in itself. Similar to Sabre, who decided against selling passenger data in 1998, many electronic marketplaces are cautious to offer such data services. At the same time, other companies have decided to pursue this business model. For example, Helloprofit, Sellics or Terapeak process and sell data from marketplaces, such as Amazon or Ebay. The topic of emerging markets for personal data has also been the special theme of an exciting issue of Electronic Markets in 2015. In their preface, the guest editors report that electronic markets exist for trading personal data itself: "On every ordinary day, Blue Kai transacts over 75 million online auctions for personal information. The company $[\ldots]$ says it owns 750 million user profiles [...] and it processes more than 30,000 attributes about these users" (Spiekermann et al. 2015, p. 91).

Interestingly, mining interaction is not limited to centralized electronic market platforms, but may also occur in decentralized markets, which feature a topology that foresees bilateral relationships among the parties involved. These direct interactions omit an intermediary and the price premium that is typically demanded by marketplace providers. On the downside is that the typical functions of a market, i.e. matching of buyers and sellers, facilitation of transactions, and provision of an institutional infrastructure (Bakos 1998, p. 35), need to be fulfilled by other mechanisms and/or actors. Among the examples are standards for product descriptions and trading procedures, such as contracting, settlement, identity and trust, as well as the programs, which embody these standards. While early approaches to decentralized markets have applied agent technology, e.g. in the fields of file sharing systems (Quiring et al. 2008) or in freight transportation
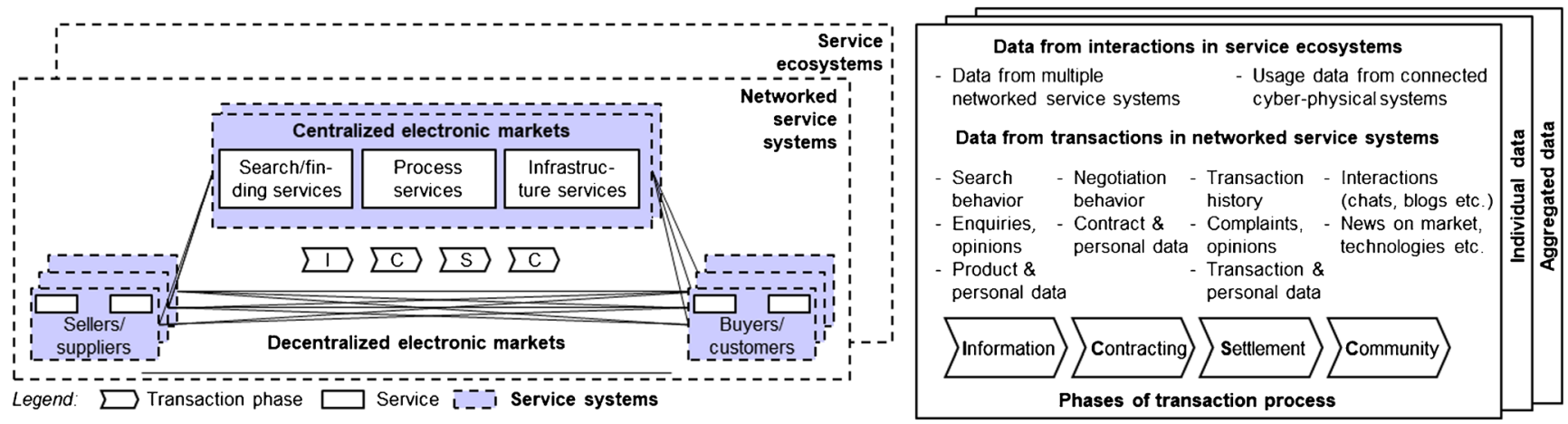

Fig. 1 Data in electronic markets 
(Föhring and Zelewski 2015), more recently internet of things (IoT), distributed ledger (DLT) or Blockchain technologies have spread (e.g. in the energy wholesale business (Peck 2017)). Due to their ability to secure trust in distributed settings, they were referred to as the "trust machine" (Economist 2015) as well as the "decentralized internet" (Carlson-Wee 2017). Although establishing profiles of customers and trading data has become more difficult in this setting, big data technologies have provided useful in analyzing decentralized transactions as well. Among the examples are the mining of EDI transactions (Engel et al. 2013) as well as of DLT transactions. For example, the company Chainalysis claims to have retrieved bitcoins that were lost during the bankruptcy of the bitcoin exchange platform Mt.Gox with their Blockchain monitoring solution (Redman 2017). Using these technologies, decentralized ledger databases could be analyzed regarding other data elements and data providers could again compile and sell profiles similar to the case of centralized markets.

\section{Service-orientation and big data}

Selling data to other businesses brings us to our second theme, service-orientation. It was in 2010, that Electronic Markets already published a special issue on "Service-orientation in electronic markets". The preface described service-orientation as a cross-disciplinary concept that is primarily grounded in business, engineering, technology and the social sciences (Alt et al. 2010, p. 177). Two perspectives shall be distinguished.

From an economic background, service industries are distinguished from goods-based industries. Services are regarded as immaterial in nature and relying on usage and the close interaction between the provider and the consumer of a service. More broadly, services may be conceived as offerings on the market that consist of "dynamic configurations of resources (people, technology, information, organizations) connected internally and externally through value propositions" (Barile et al. 2016, p. 657). This bundling of resources also led to the notion of service systems. In the context of the (big) data services mentioned above, the value propositions of these providers may be termed as "big data as a service". To support the transaction process, the service system of an electronic market bundles services in the areas of search, process/ allocation support and infrastructure (Alt et al. 2010, see also Fig. 1). Possible value propositions for big data services might pertain to offering storage infrastructure (e.g. provision of Hadoop and Spark clusters on Amazon Web Services and Microsoft Azure), analytic functionalities (e.g. provision of statistical tools as managed solution based on cloud storage) or application data (e.g. provision of consolidated/aggregated data on markets, products and/or customers).

Recent research in service science has recognized that service systems are typically linked with other service systems
(Barile et al. 2016). This may occur in dyadic relationships, which are typical for business process outsourcing as well as within network settings, which are typical for electronic markets that connect multiple buyers and sellers in a more or less dynamic fashion to meet the need of one or multiple consumers. These networked service systems may occur in centralized and decentralized electronic market environments. In addition, ecosystems have been introduced in the service science literature as a third level besides service systems and service networks. These ecosystems often also include electronic platforms, which support the integration of many resources (Barile et al. 2016, p. 654ff). This is apparent in production industries where goods and service are increasingly interrelated, e.g., as product-enabled services or 'servitization' of products or product-service-bundlings. These services are based on big data analytics, e.g., real time data generated by so-called cyber-physical systems (CPS) or IoT. Consequently, a service-related logic has become more and more common and integral to both business model design and innovation.

From a technological perspective service-orientation is also referred to as service computing, which denotes "the creation and delivery of services, which involve computing devices and software components distributed on the Web and provisioned (and often also controlled) by diverse organizations" (Bouguettaya et al. 2017, p. 67). In the big data context, the technological perspective yields a twofold picture: First, standards in the area of service-oriented architectures may be regarded as enablers of interoperable big data services, e.g. for weaving analytical functionalities, such as visualization, data enrichment or simulation and forecasting, into business processes. Standards from OASIS and others were created to enable the networking and interoperability of technological resources along the service life cycle (e.g. design and composition of services). Second, big data represents an enabler of service computing besides other technologies, such as mobile, cloud and social computing. In particular, big data technologies are believed to contribute algorithms and models for dynamically composing services online (Bouguettaya et al. 2017, p. 71). Thus, big data technologies contribute to market- or user-oriented service bundles that add value within networked service systems and/or service ecosystems, a fact also stated by Barile et al. (2016, p. 666):

"Big data need to be viewed as a service, providing a lens for seeing the market and a channel to listen to its voice. As a service, big data also can reveal service ecosystems in real time, enabling us to see and hear the sounds of the assembly and disassembly of service ecosystems. [...] Developing big data methodology and techniques thus can benefit the viability of service systems, the creation and change of service networks, and thus, our understanding of service ecosystems." 
In summary, the fields of service-orientation and big data are closer than they might appear and mutually complement each other. Both are critical for the competitiveness across industries, but both need to overcome a pure technological perspective. Ultimately, this is reflected in the growing "abstraction along the computing value chain" (Bouguettaya et al. 2017, p. 66), whereas raw data from sensors and storage media needs to be successively transformed into information with meaning based on models and purposes. Information in turn represents the basis for knowledge and, finally, for services or actions within society. In a business setting, these services add value to processes in supply chain management and production as well as in sales and marketing. However, the organization of these processes is expected to change, in particular, regarding more overall transparency, more cross-domain processes, more decentralization and more user-orientation. Customers are in a particular role as suppliers and users of data. Data on their personality and behavior allows tailored offerings and provides an opportunity to increase customer retention. Amazon was one of the first online retailers that actively pursued this approach and introduced customer reviews as early as 1995 and, only little later, recommendation services based on customer behavior data. Besides collecting data from individual transactions, data is also available from facilitating transactions with other vendors (e.g. via the marketplace) and devices in the entire ecosystem (e.g. Alexa). All of these recent innovations introduced by Amazon are merely focused on increased customer services and a better customer experience (Rigby 2017). However, customers have only little negotiation power within these ecosystems and, very often, their choices are limited to either accepting and using the offerings or to declining the terms of use and being left outside. Thus, despite the increased potential for transparency, userorientation and decentralized processes, customers often have little insight and control on the service configuration and the behavior of big data services. Solutions in the direction of more customer-orientation and customer empowerment within service networks and service ecosystems are much needed avenues for future research and have already triggered another special issue in Electronic Markets titled "Smart services The move to customer-orientation".

\section{Special issue articles}

After this general reflection on the relationship between big data and service-orientation the two special themes of the present issue of Electronic Markets comprise three articles each and are introduced by prefaces from the respective guest editors. The special issue on "Service oriented e-business development" was guest edited by our senior editor Doug Vogel and Xitong Guo, both from Harbin Institute of Technology, China, Jing Zhao and Zhen Zhu, both from
China University of Geosciences, Wuhan, and Jianqing Chen, University of Texas at Dallas. Two papers contribute examples from service industries and one papers analyzes a service platform for crowdsourcing regarding the competition intensity in contest. Interestingly, the extraction of customer opinions and product reviews in $\mathrm{B} 2 \mathrm{C}$ electronic commerce also represents a link to big data topics, thus to the second special theme of this issue.

The second special issue addresses "Big Data Analytics in Electronic Markets" and was organized by Eric W.T. Ngai, The Hong Kong Polytechnic University, Hong Kong, China, Angappa Gunasekaran, University of Massachusetts Dartmouth, USA, Samuel Fosso Wamba, NEOMA Business School, France, Shahriar Akter, University of Wollongong, Australia, and Rameshwar Dubey, Symbiosis International University, India. In their position paper published in issue $26 / 2$, two of these guest editors laid the ground by providing a systematic review and research agenda in the area of Big Data Analytics in the context of electronic markets and electronic commerce (Akter and Wamba 2016). The articles are looking at applying big data analytics to multimodal mobility platforms and predicting user behavior as well as on the measurement of investor sentiment in stock markets. We would like to express our gratitude to all guest editors for organizing the two special issues.

Finally, we would like to announce three recent developments at Electronic Markets. First, we appreciate that Electronic Markets' journal impact factor for 2016 increased to 1.864 , which marks another remarkable improvement of some $33 \%$ compared to 2015 . As described in the editorial of issue 26/2, the impact factor 2016 represents how often Electronic Markets papers published in the two previous years, i.e. 2015 and 2014, were cited in indexed journals during 2016 (Alt et al. 2016). Second, in the annual editorial board meeting of Electronic Markets held at ECIS 2017 in Guimarães, Portugal, enhancements of the editorial board were decided. It is an honor to welcome the following colleagues: Ulrike Baumöl (Fernuniversität Hagen, Germany) as new Senior Editor, Maria Madlberger (Webster Vienna Private University, Austria) and Mark de Reuver (Delft University of Technology, Netherlands) as new Associate Editors and Anastasia Constantelou (University of the Aegean, Greece), Christiane Lehrer (University of St. Gallen, Switzerland), James E. Richard (Victoria University of Wellington, New Zealand) and Nils Urbach (University of Bayreuth, Germany) as new members of the editorial board. Thanks to all of them for accepting these assignments. Third, we are indebted to Carsta Militzer-Horstmann, who acted as Executive Editor of Electronic Markets between August 2014 and June 2017. Authors, editors and reviewers alike applauded Carsta's excitement for Electronic Markets and we now wish her all the best in finishing her Ph.D. thesis. At the same time, we are happy to welcome Maxi Herzog as new 
Executive Editor. Maxi has already been Assistant Executive Editor since March 2017 and successively took over the tasks from Carsta. She was already responsible for finalizing this issue, which we hope you enjoy reading.

Your EM-team.

\section{References}

Agarwal, R., \& Dhar, V. (2014). Big data, data science, and analytics: The opportunity and challenge for IS research. Information Systems Research, 25(3), 443-448. doi:10.1287/isre.2014.0546.

Akter, S., \& Wamba, S. F. (2016). Big data analytics in E-commerce: A systematic review and agenda for future research. Electronic Markets, 26(2), 173-194. doi:10.1007/s12525-016-0219-0.

Alt, R. (2017). Electronic markets on academic supply chains. Electronic Markets, 27(2), 91-96. doi:10.1007/s12525-017-0258-1.

Alt, R., Abramowicz, W., \& Demirkan, H. (2010). Service-orientation in electronic markets. Electronic Markets, 20(3-4), 177-180. doi:10. 1007/s12525-010-0047-6.

Alt, R., Militzer-Horstmann, C., \& Zimmermann, H.-D. (2016). Electronic markets on the impact factor. Electronic Markets, 26(2), 95-101. doi:10.1007/s12525-016-0222-5.

Bakos, Y. (1998). The emerging role of electronic market-places on the internet. Communications of the ACM, 41(8), 35-42. doi:10.1145/ 280324.280330.

Barile, S., Lusch, R., Reynoso, J., Saviano, M., \& Spohrer, J. (2016). Systems, networks, and ecosystems in service research. Journal of Service Management, 27(4), 652-674. doi:10.1108/JOSM-092015-0268.

Bouguettaya, A., Singh, M., Huhns, M., Sheng, Q. Z., Dong, H., Yu, Q., Neiat, A. G., Mistry, S., Benatallah, B., Medjahed, B., Ouzzani, M., Casati, F., Liu, X., Wang, H., Georgakopoulos, D., Chen, L., Nepal, S., Malik, Z., Erradi, A., Wang, Y., Blake, B., Dustdar, S., Leymann, F., \& Papazoglou, M. (2017). A service computing manifesto: The next 10 years. Communications of the ACM, 60(4), 64-72. doi:10. $1145 / 2983528$.

Bryson, S., Kenwright, D., Cox, D., Ellsworth, D., \& Haimes, R. (1999). Visually exploring gigabyte data sets in real time. Communications of the ACM, 42(8), 82-90. doi:10.1145/310930.310977.

Carlson-Wee, O. (2017). The future is a decentralized internet. https:// techcrunch.com/2017/01/08/the-future-is-a-decentralized-internet/. Accessed 24 July 2017.
Copeland, D.G., \& McKenney, J.L. (1988). Airline reservation systems: Lessons from history. MIS Quarterly, 12(3)3, 3532-370. doi:10. $2307 / 249202$.

Economist (2015). The trust machine. https://www.economist.com/news/ leaders/21677198-technology-behind-bitcoin-could-transformhow-economy-works-trust-machine. Accessed 24 July 2017.

Engel, R., Rantham Prabhakara, J., Pichler, C., Zapletal, M., \& Werthner, H. (2013). EDIminer: A toolset for process mining from EDI messages. In: Proceedings 25th International Conference on Advanced Information Systems Engineering (CAISE'13), Valencia, 17-21 June 2013, CEUR-WS.org, vol. 998 (pp. 146-153).

Föhring, R., \& Zelewski, S. (2015). Towards decentralized electronic market places and agent-based freight exchanges for multimodal transports. In: Proceedings IEEE conference on automation science and engineering (CASE). Gothenburg. doi:10.1109/CoASE.2015. 7294070 .

Loebbecke, C., \& Picot, A. (2015). Reflections on societal and business model transformation arising from digitization and big data analytics: A research agenda. The Journal of Strategic Information Systems, 24(3), 149-157. doi:10.1016/j.jsis.2015.08.002.

Peck, M. (2017). Enerchain: A decentralized market on the Blockchain for energy wholesalers. IEEE Spectrum, http://spectrum.ieee.org/ energywise/energy/the-smarter-grid/enerchain-a-decentralizedmarket-on-the-blockchain-for-energy-wholesalers. Accessed 24 July 2017.

Press, G. (2013). A very short history of big dat. Forbes, https://www. forbes.com/sites/gilpress/2013/05/09/a-very-short-history-of-bigdata/\#881c8c65a184. Accessed 12 July 2017.

Quiring, O., von Walter, B., Atterer, R., \& Hess, T. (2008). Decentralized electronic markets: Exploring the effects of revenue splitting inside file sharing systems. Electronic Markets, 18(2), 175-186. doi:10. 1080/10196780802045062.

Redman, J. (2017). Chainalysis says they've found the missing $\$ 1.7$ billion dollar Mt Gox bitcoins. https://news.bitcoin.com/chainalysissays-theyve-found-the-missing-1-7-billion-dollar-mt-gox-bitcoins/. Accessed 24 July 2017.

Rigby, D. K. (2017). The Amazon-whole foods deal means every other Retailer's three-year plan is obsolete. Harvard Business Review. https://hbr.org/2017/06/the-amazon-whole-foods-deal-meansevery-other-retailers-three-year-plan-is-obsolete. Accessed 24 July 2017.

Spiekermann, S., Böhme, R., Acquisti, A., \& Hui, K.-L. (2015). Personal data markets. Electronic Markets, 25(2), 91-93. doi:10.1007/ s12525-015-0190-1.

Swift, R. S. (2001). Accelerating customer relationships: Using CRM and relationship technologies. Upper Saddle River: Prentice Hall. 